\title{
Yo no me siento contigo. Educación y racismo en pueblos afromexicanos
}

\section{"I'm Not Sitting Next To You". Education and Racism in Afromexican Villages}

DOI: https://doi.org/10.32870/dse.v0i13.227

Cristina Verónica Masferrer León*

\author{
A Patricia Méndez, Angustia Torres \\ y todas las maestras y maestros \\ que luchan contra el racismo.
}

Resumen: En la actualidad, la mayor concentración de población afromexicana se ubica en la región Costa Chica de Guerrero y Oaxaca, si bien su presencia también es importante en otras zonas y entidades de la República. Durante el periodo virreinal, las contribuciones sociales, culturales, económicas y políticas de los africanos y afrodescendientes fueron significativas a lo largo de todo el territorio que hoy es México. A pesar de ello, el racismo y la discriminación son procesos históricos que han coadyuvado a su invisibilización y exclusión.

Este artículo busca reflexionar en torno al racismo en ámbitos escolares de localidades afromexicanas de la Costa Chica. Para lograrlo, se parte de las relaciones entre pares para mostrar cómo el acoso escolar reproduce el racismo. Asimismo, se muestra el papel que tienen los docentes en este proceso, ya que algunos se ocupan de esta problemática y colaboran a combatirla mientras que otros reproducen ideas racistas y prácticas discriminatorias. Así, aunque en cierta forma la educación escolar promueve conocimientos en torno a la discriminación, la escuela es un espacio donde el racismo se aprende y se vive; por ejemplo, a partir del bullying, de un trato diferenciado por parte de ciertos docentes o mediante los libros de texto de la SEP, que niegan o minimizan la presencia y los aportes de los afrodescendientes en México. Palabras clave: racismo, discriminación, educación, niñez, afrodescendientes.

\begin{abstract}
Today, the biggest concentration of Afro-Mexican communities is found in the Costa Chica region of Guerrero and Oaxaca, although their presence is also important in other areas and states of Mexico. The social, cultural, economic, and political contributions of Africans and their descendants were significant during the colonial period throughout the territory known today as Mexico. Still, historic processes of racism and discrimination have led to their invisibilization and exclusion.

This paper is a reflection on racism in schools of Afro-Mexican communities in the Costa Chica region. It presents an analysis of interactions between students, showing how bullying reproduces racism in school, as well as the role of teachers in this process, with some confronting the problem and collaborating to eradicate it and others reproducing racist ideas and discriminatory practices. Therefore, although school education promotes learning about discrimination to a certain degree, it also constitutes a space where racism is learned and lived, either in cases of bullying, in discriminatory attitudes by certain teachers, or in official textbooks that deny or minimize the presence and contributions of African descendants in Mexico. Key words: racism, discrimination, education, childhood, African descendants.
\end{abstract}

* Maestra en Antropología Social. Investigadora del equipo Oaxaca en el Programa Nacional de Investigación "Etnografía de las regiones indígenas de México", INAH. Correo electrónico: cristinamasleon@gmail.com 
Las clases habían terminado y los alumnos estaban listos para regresar a casa pero aún jugaban en el patio de una escuela de Cuajinicuilapa, una localidad considerada afromexicana ${ }^{1}$ ubicada en la región Costa Chica del estado de Guerrero. Antes de retirarse, Rosa, una estudiante de quinto grado de primaria, me contó la historia que conocía sobre los negros y morenos. ${ }^{2}$ Se trata de una historia local que circula en la zona acerca de un barco que naufragó y en el cual se dice que venían las personas de origen africano que poblaron la región:

Porque a mí me contaron que una vez llegó un barco en un pueblito. Y ya llegó un barco y había muchos negros. Y un día el barco, se hundió el barco, se hundió, y decía la gente que salían, uno por uno, salía la gente. Y decían que llegaron en ese pueblito y que se casaban y tenían niños y se hacían más muchos (Rosa, entrevista, 2012).

Rosa me explicó que los "negros" se casaban con los "morenos", porque los "blancos" no querían casarse con ellos. Entonces, le pregunté cómo se podía saber si alguien es moreno, a lo cual respondió -como si fuera algo obvio-, "porque está moreno". Le insistí: "¿Y si no puedes ver? ¿Si cierras los ojos y no puedes ver, cómo puedes darte cuenta si es moreno o no?". "Preguntándole", contestó Rosa. Como en un juego, le pedí que imaginara que no podía ver ni hablar, pero podía escuchar. Pensé que mencionaría la manera de hablar de las personas ya que en la región ello suele señalarse como una característica de estas poblaciones. En cambio, Rosa cerró los ojos y después de un momento respondió: "Puedo escuchar que le dice uno: yo no me siento contigo porque tú eres moreno" (entrevista, 2012).

Las expresiones de Rosa reflejan sus conocimientos sobre los afromexicanos, pero también sus experiencias en torno a la discriminación hacia las personas consideradas negras o morenas. La decisión de sentarse, o no, junto a alguien dependiendo de su identidad étnica, de la percepción sobre su tono de piel o de la "raza" ${ }^{3}$ que se le impone -así como el hecho de decírselo-, es una de las formas en que se presenta el racismo y la discriminación en los contextos escolares a los cuales Rosa y otros niños están acostumbrados.

Este tipo de prácticas racistas me recuerdan la vivencia de una mujer negra de la Costa Chica quien, después de años de vivir en la ciudad de Oaxaca, enfrentó este tipo de experiencia en un autobús; varias personas prefirieron permanecer de pie en lugar de sentarse a su lado (comunicación personal, 2015). Si vamos un poco más allá, podemos recordar lo ocurrido en un contexto lejano en tiempo y espacio. En 1955, en Estados Unidos, Rosa Parks se negó a levantarse de su asiento

1 El término afromexicano es utilizado en las constituciones de Oaxaca y Guerrero; hace referencia a las poblaciones mexicanas, históricamente asentadas en el país, que descienden de los hombres y mujeres africanos que fueron víctimas del comercio de personas esclavizadas entre los siglos XVI y XIX (véase: Conapred, 2011).

2 "Negros" y "morenos" son los principales términos de autoadscripción y heteroadscripción de esta población en la región Costa Chica. Ambas palabras eran utilizadas desde el periodo virreinal. Varias organizaciones y personas de la Costa Chica de Oaxaca y Guerrero reivindican los términos pueblo negro y negro afromexicano.

3 Las razas humanas no existen en términos biológicos (Lewontin, 1972). Por tanto, en este trabajo entiendo "lo racial" como una construcción social, histórica, ideológica y política que imagina o inventa la existencia de razas e impone esta categoría a las personas y poblaciones, a pesar de que no respondan a ninguna realidad biológica (Hoffmann, 2008). 
para que un "blanco" se sentara, en una época en que el racismo de ese país llegaba a tal punto que los afroestadounidenses o negros debían sentarse en la parte trasera del transporte dejando los lugares del frente para los "blancos". Se trata de contextos históricos, sociales y políticos sumamente diferentes, pero en ambos casos lo que hay detrás de la práctica racista es la inferiorización del otro, y el consiguiente rechazo a estar juntos. Así, la elección de con quién sentarse y con quién no hacerlo no es casual sino que puede enmarcarse dentro de las experiencias racistas que niños y adultos enfrentan en su cotidianeidad.

El objetivo de este artículo es reflexionar en torno al racismo y la discriminación racista en ámbitos escolares de la Costa Chica de Guerrero y Oaxaca. Parto de las relaciones entre pares para mostrar cómo el bullying o acoso escolar en ocasiones opera como una forma de reproducción del racismo. Asimismo, doy cuenta de experiencias de racismo y discriminación en la escuela que muestran la participación de algunos docentes en estos procesos, a pesar de que haya otros que luchan en contra de la discriminación. Este estudio se desprende de mi trabajo de campo realizado en varias localidades de la Costa Chica de Guerrero y Oaxaca, principalmente en los municipios de Cuajinicuilapa y Santa María Huazolotitlán, entre 2011 y 2013. Empleé métodos y técnicas como la etnografía, la etnografía educativa y las entrevistas con niños y adultos; además, impartí talleres con docentes, así como talleres de radio y de pintura con niños (véase: Masferrer, 2014b).

Es pertinente subrayar que muchas veces son los docentes, los directores, los padres y los propios niños quienes procuran evitar este tipo de prácticas, a pesar de que haya otros maestros, familiares y alumnos que ejercen y reproducen el racismo. Por tanto, de ningún modo busco reducir a los actores sociales con quienes trabajé a las situaciones racistas en que se ven involucrados; por el contrario, mi interés es dar cuenta de la complejidad de estas experiencias dolorosas que menoscaban los derechos humanos, vulneran la dignidad y lastiman la autoestima de niñas, niños, mujeres y hombres. Igualmente, las poblaciones afromexicanas o negras de la Costa Chica cuentan con un patrimonio cultural e histórico amplio, así que su diversidad y riqueza cultural no se limitan a las experiencias de racismo y discriminación que enfrentan y las cuales ellos mismos buscan erradicar. Así, la finalidad de visibilizar esta problemática es coadyuvar a entenderla y eliminarla.

\section{La Costa Chica: el contexto de la investigación}

La región conocida como Costa Chica es una franja costera ubicada a orillas del océano Pacífico que se extiende, aproximadamente, desde Acapulco hasta Huatulco, en los estados de Guerrero y Oaxaca. En ella convive población afromexicana e indígena (sobre todo mixtecos, chatinos, amuzgos, tlapanecos y nahuas), así como personas que no se consideran parte de ninguno de estos grupos. En la actualidad el mayor asentamiento afromexicano se ubica en la región Costa Chica (CDI, 2012; INEGI 2015). No obstante, es pertinente mencionar que, históricamente, la presencia de africanos y afrodescendientes se extendió a lo largo de todo el territorio mexicano desde el periodo virreinal y también después de la Independencia. Además, las contribuciones económicas, sociales, 
culturales y políticas de las miles de personas de origen africano han sido profundamente significativas en la construcción de México.

La reciente Encuesta Intercensal 2015 del INEGI indica que en México hay 1.4 millones de personas que se consideran afrodescendientes y los porcentajes más altos se encuentran en Guerrero y Oaxaca, aunque su presencia es importante también en otros estados como Veracruz, el Estado de México y la Ciudad de México (INEGI, 2015). Asimismo, en 2013 este mismo instituto publicó el Perfil sociodemográfico de localidades con presencia de población afromexicana de Oaxaca, con información acerca de 106 localidades oaxaqueñas donde se considera que hay población afromexicana (INEGI, 2013).

Además de este aspecto demográfico es oportuno considerar que existen varias organizaciones de la sociedad civil que, desde la década de 1990, reivindican los derechos de esta población, luchan contra la discriminación que enfrenta y pugnan por lograr su reconocimiento constitucional en el ámbito federal. Algunas de estas organizaciones son México Negro AC, AFRICA AC, Taller Cultural Cimarrón, EPOCA AC, ECOSTA Yutu Cuii SSS, Red de Mujeres Afromexicanas AC, Asociación de Mujeres de la Costa de Oaxaca AC, Socpinda DH AC, entre otras.

En palabras del actual presidente de la organización México Negro AC, Sergio Peñaloza, la discriminación fue "el primer elemento para entrar a un proceso de lucha como éste, y en ese caminar nos fuimos encontrando con muchas cosas, como el rescate de la cultura, que servía para la visibilización de lo que era negado, de los negros, y todo eso después se derivó en el reconocimiento constitucional" (entrevista, 2012).

\section{Breve estado de la cuestión}

Existen investigaciones históricas y antropológicas acerca del racismo en México, sobre todo hacia poblaciones indígenas y migrantes (Castellanos y Sandoval, 1998; Castellanos, 2000 y 2003; Gómez, 1991 y 2005; París, 1999; Urías, 2007; Yankelevich, 2009; Gall, 2004). Igualmente, se ha analizado cómo el racismo se expresa en las políticas de educación intercultural, así como en planes, programas y libros de texto (Molina, 1995; Gnade, 2008; Aguilar, 2012; Baronnet, 2013; Ballesteros, 2014; Gallardo, 2014; Barquín, 2015; Velasco, 2016). Destacan los estudios que abordan esta problemática entre poblaciones indígenas, a veces vinculada a la migración o a la desvalorización de sus lenguas en el contexto escolar (Barrón, 2008; Martínez Buenabad, 2008; Coronado y Mena, 2010).

En cambio, el racismo escolar hacia las poblaciones afromexicanas ha sido mucho menos abordado. En trabajos previos he expuesto cómo los libros de texto de primaria y telesecundaria de la Secretaría de Educación Pública (SEP) reproducen ideas y estereotipos racistas mediante la enseñanza de contenidos que hacen referencia a la diversidad humana en términos de razas y que niegan o minimizan los aportes de las poblaciones de origen africano (Masferrer, 2011 y 2014a). Otros estudios han tratado la reproducción de este tipo de ideas con relación a los indígenas (Mo- 
lina, 1995; Gnade, 2008), basándose en los materiales educativos anteriores a la Reforma Integral de Educación Básica (RIEB). ${ }^{4}$

Los materiales posteriores a la RIEB que la SEP produce y obliga a utilizar en todas las escuelas del país suelen reducir a las personas africanas y afrodescendientes a "negros" y "esclavos", sin brindar oportunidades para apreciar la heterogeneidad de las culturas africanas a través del tiempo o de las poblaciones afrodescendientes en América y, en particular, en México (Masferrer, 2011 y 2014a). Del mismo modo me he ocupado de las experiencias de docentes y alumnos en torno a estos contenidos en la Costa Chica, para trascender el análisis de textos escolares y aproximarme a las prácticas racistas y discriminatorias (Masferrer, 2014b y en prensa). Así, el presente artículo busca ampliar la discusión sobre las experiencias de racismo y discriminación en contextos escolares donde la presencia afromexicana es sumamente relevante.

\section{Notas conceptuales: prejuicio, estereotipo, racismo y discriminación racista}

De acuerdo con Allport (1954: 9), el prejuicio étnico es una antipatía basada en una generalización inflexible e imperfecta; puede ser expresada o simplemente sentida; y puede ser dirigida a un grupo en general o a un individuo por pertenecer a ese grupo. Esta actitud se nutre de estereotipos, es decir, generalizaciones o sobre-generalizaciones acerca de un grupo (Plous, 2003: 1). Tal como lo afirma Eduardo Restrepo, se trata de imágenes e ideas prefabricadas que se proyectan sobre un grupo de personas, las cuales "generalmente caricaturizan erróneamente las características y comportamientos de quienes son estereotipados" (Restrepo, 2012: 179).

La discriminación se relaciona con los prejuicios y los estereotipos a pesar de que se trate de fenómenos diferentes, pues la discriminación es ante todo una conducta que implica tratar de manera diferente a ciertas personas ocasionándoles una desventaja que restringe sus derechos de alguna manera (CNDH, 2012: 6). Me parece pertinente recuperar la definición de Jesús Rodríguez, para quien la discriminación es:

Una conducta, culturalmente definida, y sistemática y socialmente extendida, de desprecio contra una persona o grupo de personas sobre la base de un prejuicio negativo o un estigma relacionado con una desventaja inmerecida, y que tiene por efecto (intencional o no) dañar sus derechos y libertades fundamentales (Rodríguez, 2008: 26).

Uno de los aspectos a destacar de esta manera de comprender la discriminación es que se trata de una conducta sistemática, extendida y definida cultural e históricamente cuyas consecuencias a menudo son intencionales, pero pueden no serlo. Este punto es fundamental para lograr que el análisis del racismo y la discriminación trascienda la culpa y, en su lugar, se centre en la sensibilización y la concientización de sus complejos motivos y efectos.

4 La RIEB inició en 2004 con el nivel preescolar, continuó en 2006 con secundaria y culminó con la primaria entre 2009 y 2011 (véase también: Gallardo, 2014). 
De acuerdo con el antropólogo Eduardo Restrepo (2012: 176), la discriminación "supone la doble articulación de un acto de diferenciación y un ejercicio de exclusión". Por tanto, es importante examinar los criterios de diferencia que se toman en cuenta para categorizar a las personas, así como la manera en que se excluye a aquellos considerados como diferentes. Las principales formas de exclusión son el rechazo, la negación y el desconocimiento, las cuales pueden limitarse al plano del pensamiento o expresarse en conductas específicas.

Por su parte, el racismo es un fenómeno ideológico, político y doctrinario, que además implica un conjunto de prácticas y conductas entre personas y grupos humanos que toman la forma de prejuicios, estereotipos, segregación, exclusión y discriminación (Wieviorka, 2009: 51-52). A pesar de que se ha demostrado que biológicamente las razas humanas no existen ( $c f r$. Lewontin, 1972; Ramírez, 2007 y 2009), especialistas como Wieviorka (2009: 13) señalan que el racismo caracteriza a "un conjunto humano mediante atributos naturales, asociados a su vez a características intelectuales y morales aplicables a cada individuo relacionado con este conjunto" y, a partir de ello, adopta "prácticas de inferiorización y exclusión".

Así, podemos considerar al racismo como una forma de discriminación que se articula en torno a lo racial, tal como lo hace Eduardo Restrepo (2012: 177). No obstante, en este artículo utilizo el término discriminación racista -en lugar de discriminación racial-, con la finalidad de subrayar la inexistencia de las razas, la artificialidad de lo racial y la vinculación de esta forma de discriminación con el racismo.

\section{"Sentirse mal": definiciones cotidianas y escolares sobre la discriminación}

Para niñas y niños que cursan quinto y sexto grado de primaria en una escuela de la Costa Chica de Oaxaca, la discriminación se refiere a los insultos o los apodos que unos dicen a otros y tiene como consecuencia el "sentirse mal". Este tipo de prácticas fue considerado algo negativo por los niños y niñas que participaron en una entrevista colectiva realizada en 2013. En voz de Frida Tejada, de quinto grado: "la discriminación es mala porque así demuestras que no tienes valores ni igualdad" (entrevista, 2013).

De acuerdo con estos niños de 10 a 12 años aproximadamente, se discrimina a otros por tener alguna "discapacidad", por el "color" de la piel, por su "raza", su forma de ser, su forma de hablar, por tartamudear, por su situación económica, por vestir de otra manera o por ser "gorditos" o "flaquitos". Cualquier motivo puede ser suficiente para molestar a otros o ponerles apodo; por ejemplo, a una niña le dicen "diente mocho" porque tiene un diente roto; a un niño lo llaman "trompa de garza" porque tiene los labios gruesos; a otro lo molestan por tener los pies largos y a otra niña le dicen "gorda malvada". Así, el color de la piel, la "raza" y el origen étnico o racial que se atribuyen no son los únicos motivos para molestar a otros; sin embargo, este tipo de casos también fueron mencionados por los niños, con apodos como: "tortilla quemada", "negrito Bimbo" o "india patarrajada". 
En los libros de texto de la SEP de la materia Formación cívica y ética $\left(1^{\circ}\right.$ a $6^{\circ}$ grado), se trabaja el tema de la discriminación, pero no se dan suficientes herramientas o estrategias para facilitar su comprensión o para concientizar a los alumnos acerca de su importancia. Se hace hincapié en la discriminación por género o sexo y diversidad étnica, pero en el caso de la discriminación por tono de piel y por "raza" se hacen sólo menciones escuetas. Además, en ninguno de los libros se explica que las razas humanas no existen en términos biológicos.

En el libro de Formación cívica y ética de sexto grado de primaria, la discriminación se define como distinguir, excluir o restringir los derechos de otras personas con base en "su origen social o nacional, la lengua que habla, su religión, la edad que tiene, alguna discapacidad que presente, su apariencia, su identidad de género u orientación sexual; en fin, cualquier rasgo que la identifique" (Álvarez et al., 2011b: 55). Una definición similar se presenta en el libro de quinto grado de esta misma materia: "discriminar significa tratar injustamente a otras personas o a un grupo de personas porque son diferentes". De acuerdo a este libro, se puede discriminar por pensar distinto, por vestirse de otra manera, practicar religiones diferentes, tener otro color de piel o venir de otros pueblos, ciudades o países. Se explica, además, que tratar mal a las personas no sólo se refiere a "verlas con desprecio", sino que también es "negarles el derecho de ser lo que son o impedir que tengan las mismas oportunidades y servicios que todos... Discriminar es no respetar la forma de ser y de pensar de cada persona y obstaculizar sus derechos" (Álvarez et al., 2011a: 63).

Como puede verse, al contrastar las respuestas de los niños con las definiciones de discriminación de los libros de texto, la educación escolar tiene una influencia en las nociones que ellos construyen acerca de la discriminación, pero las explicaciones que dieron acerca de este fenómeno no se centran en la privación de un derecho, sino más bien en las agresiones verbales entre pares. Ello muestra una de las maneras en que las definiciones de discriminación que se trabajan en el plano científico y jurídico son traducidas en la cotidianidad por niñas y niños de un contexto particular.

\section{Experimentar el racismo y la discriminación racista en la escuela}

La educación y la no discriminación son derechos de la infancia, de ahí la importancia de que en la escuela prive un ambiente de respeto y trato igualitario para todas y todos, además de que se trata de un espacio proporcionado por el Estado. Sin embargo, persiste la discriminación en ámbitos escolares de la Costa Chica. Al respecto, la maestra Patricia Méndez, miembro de México Negro AC, directora y profesora de nivel primaria en Guerrero, explica:

Sí hay discriminación aquí, yo vivo con los compañeros, viendo cómo los discriminan [a los niños]. Los compañeros maestros y el niño, el niño es de piel oscura y luego es de bajos recursos, es más la discriminación... lo sientan a un lado, no le hacen caso (Patricia Méndez, entrevista, 2012). 
Además, es común escuchar en foros donde participan personas afromexicanas, experiencias donde se les ha excluido de la escolta escolar a pesar de tener las mejores calificaciones o incluso el mejor promedio del grupo. Estos testimonios se han hecho en público, con lágrimas en los ojos y la voz entrecortada, reflejando lo doloroso de este tipo de vivencias que implica un acto de diferenciación y exclusión.

Asimismo, en dos de los talleres que he impartido con docentes de la región Costa Chica, directoras y maestras han insistido en que sus alumnos negros son menos inteligentes y más flojos que los demás (Masferrer, 2014a y en prensa). Este tipo de ideas tienen su origen en el racismo pseudocientífico de los siglos XVIII, XIX y XX, el cual proponía bases supuestamente científicas para explicar las diferencias entre las razas humanas, estableciendo una jerarquía entre ellas y asignando a cada una cierta capacidad de inteligencia, fuerza física o características morales fijas (Velázquez e Iturralde, 2012: 90-91). Aunque se ha demostrado que estas creencias carecen de todo sustento científico, es preocupante que continúen circulando entre docentes y autoridades escolares, puesto que pudieran reflejarse en un trato diferenciado hacia niñas, niños y adolescentes afectando severamente su proceso educativo.

De acuerdo a la Convención sobre los Derechos del Niño, la educación debe favorecer el desarrollo de "la personalidad, las aptitudes y la capacidad mental y física del niño hasta el máximo de sus posibilidades"; y se debe "inculcar al niño el respeto de sus padres, de su propia identidad cultural, de su idioma y sus valores, de los valores nacionales del país en que vive, del país de que sea originario y de las civilizaciones distintas de la suya" (UNICEF). Por tanto, debemos preguntarnos en qué medida un ambiente escolar donde haya comentarios o insultos por el origen étnico y la apariencia física favorece, o no, los aspectos señalados. También debe recordarse que los libros de texto reproducen una visión parcial de la historia que no muestra las contribuciones de los miles de africanos y afrodescendientes que colaboraron en la construcción de México, y los afromexicanos que son parte de este país en la actualidad (Masferrer, 2011 y 2014a).

El bullying o acoso escolar puede ser una experiencia de violencia tan fuerte para las y los niños, que se vulnera su derecho a la educación y a la no discriminación. Por tanto, las agresiones verbales entre pares no deben ser comprendidas como parte del sentido del humor cotidiano ni las experiencias habituales de contextos escolares, pues más que una opinión individual el bullying que se asocia al racismo forma parte de una práctica cultural e históricamente fundada, sistemática y socialmente extendida, retomando la definición de Rodríguez Zepeda (2008) sobre la discriminación.

El niño del cual hablaré enseguida no abandonó su educación escolarizada pero tuvo que cambiar de escuela. Él, como otros niños, fue a uno de los colegios de nivel primaria que hay en una localidad afromexicana de la costa oaxaqueña para cursar el primer grado. Los niños le pegaban mucho, así que su madre habló con la maestra pero ella no hizo caso o, cuando menos, el problema continuó. La profesora argumentó que eso ocurría en momentos en que ella no estaba con los niños, 
por ejemplo durante el recreo, y que por eso no se daba cuenta. Dado que las agresiones físicas y verbales continuaban, la señora decidió inscribirlo en el plantel de otro pueblo, una localidad cercana al lugar donde reside. Se trata de una escuela unitaria con dos grupos, de modo que cada docente se encarga de tres grados (Diario de campo, 2013).

Le pregunté por qué lo molestaban y la madre me explicó que lo hacían porque es "muy moreno". Recordó que le decían "mole negro" y añadió: "yo ya sé que estoy negra pero no quiero que me lo anden diciendo; acá de por sí somos de raza negra; acá somos morenos todos" (Diario de campo, 2013). Ella explicó a su hijo que no debía sentirse mal, que es su color, y que es porque ella es morena y su papá es "güero". Incluso le levanta los ánimos porque su hermanito "es el más güero de la escuela", señaló. El hermano menor estaba a su lado en ese momento y afirmó que otros niños de su escuela también son güeros, pero la mamá insistió en que él es el "más" güero. Como puede verse en este caso, las experiencias de discriminación racista en ambientes escolares se relacionan con lo que ocurre en el ámbito familiar, donde no necesariamente se presenta una exclusión, pero al menos se señalan las diferencias del tono de la piel. ${ }^{6}$

Las experiencias de discriminación por el tono de piel no se viven únicamente en el nivel primaria, sino que también ocurren en preescolar. Una señora llamada Guadalupe relató que en el jardín de niños de su pueblo molestaban a su hija "porque está morena". Un día dejó a su hija en la escuela y escuchó que otras niñas decían que no se juntaran con ella. Guadalupe se molestó mucho por la situación y les preguntó por qué decían eso. Las niñas le respondieron: "porque [ella] está negra y nosotras estamos güeras" (entrevista, 2013). La señora les rebatió y además acudió con la maestra para que interviniera.

En ese momento, Guadalupe se enojó tanto por la situación que les dijo a las niñas: “tú crees que porque estás güera, le digo, ¿tú qué?, por más güera que estés o como estés, estás fea por lo que haces, mi hija esté fea y esté como esté, pero para mí es bonita". Ella piensa que su hija "no desearía estar morena pero, al menos, le digo, yo no me molesto porque mis hijos sean morenos" (entrevista, 2013). Estas reacciones dejan ver un racismo interiorizado tanto en la propia niña como en la madre, al sugerir que ser negra o morena es algo negativo que se asocia a la fealdad. Además de ello, el motivo de ser negra o morena despierta inquietudes en la niña, quien ha preguntado a su madre por qué ella es morena y su madre es güera. La señora Guadalupe le explica que se debe a que su papá y su tía son morenos, aunque "también por el sol, más que nada" (entrevista, 2013).

En abril de 2013, la hija de la señora Guadalupe y varios compañeros de grupo participaron en un baile infantil durante un acto público relevante en el pueblo. Las maestras del preescolar cubrieron el rostro, las piernas y los brazos de los niños con una sustancia negra, pues consideraron que

5 En algunos contextos mexicanos la palabra "güero" se emplea para referirse a las personas con cabello rubio y piel clara. En la Costa Chica este término se refiere a las personas con un tono de piel más claro que la mayoría de la gente en esa región, aunque no tengan el cabello rubio.

6 Para un análisis sobre la socialización racial en la familia véase: Correa, 2013. 
no tenían la piel suficientemente oscura y se trataba de representar al pueblo "negro afromexicano". Bailaron dos canciones, "El negrito bailarín" de Francisco Gabilondo Soler Cri Cri, y "La negra tiene tumbao", de Celia Cruz. Ambas canciones insisten en la supuesta disposición de los negros a la música, el baile, la pereza y la sexualidad -todos ellos estereotipos que han pesado históricamente sobre las poblaciones afrodescendientes-. Además, pintar de negro el cuerpo de los alumnos pudiera reiterar el estereotipo de que la población afromexicana o negra puede reducirse a un aspecto somático, sin olvidar que se trata de una vivencia significativa para las y los niños quienes lo experimentaron en sus propios cuerpos. Durante la presentación, algo más llamó poderosamente mi atención: habían tiznado a todos los que participaron, excepto a la hija de la señora Guadalupe.

A este respecto es importante insistir en que las maestras del preescolar de ninguna manera incurrieron intencionalmente en un acto de racismo o de discriminación. Por el contrario, ellas buscaban participar en un evento donde se reivindicaba a las poblaciones afromexicanas o negras. Al hablar con una de ellas al respecto, señaló que algunas niñas tenían la piel "blanca" y fue por eso que les tiznaron para poder representar a los negros; no parece haber advertido que a la única que no pintaron de dicho color fue a la niña de quien he hablado. En este sentido vale recordar que la discriminación se define de acuerdo a sus consecuencias y no necesariamente a partir de la intencionalidad. Así, Philomena Essed (1991: 39) explica que, desde un punto de vista macro, el racismo es un sistema de desigualdades estructurales y un proceso histórico, creados y recreados mediante prácticas rutinarias mientras que, desde una perspectiva micro, se trata de un conjunto de prácticas consistentes con las estructuras macro de desigualdad racial del sistema y cuyas consecuencias pueden ser intencionales o no.

En cambio, luchar contra la discriminación requiere de un esfuerzo intencional e incluso preparación al respecto. La maestra Angustia Torres, con quince años de experiencia docente, y miembro de AFRICA AC, me comentó que hace años tenía un alumno al que molestaban por ser negro. El niño se le acercaba para preguntarle si Dios no los quería igual a todos: "y por qué a unos le da el cuero blanco y por qué a mí me echó todo quemado afumado y para que mis compañeros se rían de mí o para que mis compañeros no quieran jugar conmigo" (Angustia Torres, entrevista, 2013). La profesora Torres reconoció: "esa es una discriminación bárbara porque quieras o no vas creciendo con eso y te afecta, te afecta, yo me fijaba en el niño de que era, hasta cierto punto, después de algunos meses, violento" (entrevista, 2013). Después de años de ser parte de AFRICA AC, ella conoce más al respecto de la discriminación, de modo que puede acercarse a los niños y sus familiares para evitar ese tipo de situaciones.

De acuerdo con el testimonio de Angustia Torres, el niño "era objeto de burla, porque ni siquiera lo llamaban por su nombre", sus compañeros le decían sorullo ${ }^{7}$ o lo molestaban expresando:

7 De acuerdo al Diccionario de la Real Academia Española, sorullo es un "tabaco mal torcido y de baja calidad", sin embargo, pudiera derivarse o relacionarse con el término "zurullo" que hace referencia al excremento (Consúltese: http://dle.rae.es). 
"ahí viene el negro choco, no se junten con él". Choco es una palabra que en la región se emplea para referirse a lo sucio. Ciertos contenidos de los libros de texto de la SEP reproducen ideas que también vinculan a lo negro con lo sucio, lo negativo y la fealdad. Paradójicamente, el siguiente ejemplo procede del libro de quinto grado de la materia Formación Cívica y Ética.

En una de las páginas de este libro se presenta un dibujo que muestra a un hombre "negro" desnudo sentado dentro de una tina con agua, quien mantiene una actitud pasiva frente a un hombre blanco y vestido, arrodillado fuera de la batea. Arriba de dicha imagen se despliega el siguiente texto de la fábula de Esopo titulada "El negro":

Un hombre compró a un negro; pensaba que por falta de cuidado había ennegrecido, que nunca se había bañado desde que entró a servir, así que empezó a bañarlo y a lavarlo a diario; mucho enjabonaba, frotaba su cuerpo, pero no por eso dejaba el negro su color, su negrura, antes con ello empezó a enfermar, murió. Esta fábula nos enseña que el modo de ser con que nació cada uno no hay nadie que se lo haga cambiar por otro (Álvarez et al., 2011a: 62).

Este escrito reduce a los negros a la esclavitud y la servidumbre: "un hombre compró a un negro"; poco importa su origen étnico, pues para este libro de la SEP este hombre no es un wolof, ni un mandinga, ni un africano o afrodescendiente, es simplemente un "negro". Este hombre no parece tomar ninguna decisión por sí mismo, sino que se le representa como insensible e inactivo frente a las elecciones de quien lo compró; el "negro" enferma y muere a causa de dicha pasividad. Por si esto fuera poco, se asocia a lo negro con lo sucio, lo desagradable, lo negativo: "pensaba que por falta de cuidado había ennegrecido, que nunca se había bañado desde que entró a servir".

La moraleja de esta fábula tampoco se relaciona con la no discriminación, sino que enseña que no se puede cambiar la forma como uno nació. El libro parece sugerir que este hombre nació con una enorme dificultad para bañarse, ya que murió a causa de ello, y con una imposibilidad para tomar decisiones por sí mismo. Así, se reproduce la idea de que nació para ser esclavizado ${ }^{8}$ Es necesario precisar que probablemente éste no era el sentido que la fábula tenía para Esopo, filósofo griego del siglo VI a. C., quien al parecer fue esclavizado y después liberado. Para el análisis de esta fábula habría que considerar el contexto y la vida de Esopo, sin embargo, en el libro de la SEP no se proporcionan datos al respecto, de modo que el lector se queda únicamente con la información disponible. También es importante recordar que la esclavitud se asoció a la población de origen africano sólo después del siglo XV, cuando se generalizó la trata o comercio transatlántico de personas esclavizadas, mientras que previamente la esclavitud no era, necesariamente, de africanos y

8 Filósofos griegos de la antigüedad, como Aristóteles, señalaban que algunos hombres habían nacido para ser esclavizados y otros para ser amos: "la naturaleza... por miras de conservación, ha creado ciertos seres para mandar, y otros para obedecer” (Saco, 2002: 230). Estas ideas se reprodujeron en siglos posteriores, por ejemplo, en el siglo XVI Palacios Rubios señalaba que algunos hombres "no parecen sino nacidos para el mando y la dominación, al tiempo que otros son tan toscos y obtusos que parecen destinados a obedecer y servir", "desde el momento mismo en que fueron engendrados los unos son señores, los otros siervos, existe, pues, una situación natural para la existencia de amos y esclavos” (Moreno, 2003: 49-50). 
afrodescendientes (Velázquez e Iturralde, 2012). Este hecho sin duda marca una diferencia en la lectura e interpretación de la fábula, pero se trata de un dato que los docentes y alumnos no tienen a la mano.

Me he centrado en experiencias de discriminación racista hacia niñas y niños considerados negros o morenos. No obstante, indígenas y afrodescendientes no sólo comparten el espacio en el que viven, sino también muchas de las situaciones de racismo y discriminación, así como las condiciones de desigualdad social y económica. El maestro Hermenegildo Albino, profesor de una escuela de la Costa Chica, indicó: "veo un niñito que luego lo empiezan a discriminar aquí porque como la mayoría es de raza morena o negra, le empiezan a decir no, es que tú eres un indio, lo discriminan" (entrevista, 2013). También escuché que algunos niños usaban la palabra choco (sucio) para referirse a los indígenas ("indio choco").

Tal como muestro enseguida, la discriminación hacia niños indígenas y afromexicanos en la región pudiera mantener matices con respecto a otros actos de diferenciación y exclusión; no por ello menos injustos y violatorios de los derechos humanos, pero sí percibidos de manera atenuada por los propios actores. Me encontraba dentro del salón de quinto grado de una escuela en la Costa Chica de Guerrero, cuando un alumno de quinto grado se sentó a mi lado y me confesó: "aquí todos me discriminan por ser güero", y añadió que por ese motivo solía quedarse en el salón durante el recreo. Se trata de un niño que había llegado recientemente de una ciudad del norte del país de modo que su condición de migrante se aunaba a la diferencia percibida sobre su tono de piel. Le argumenté: "pero no tiene nada de malo ser güero", a lo cual respondió casi de inmediato: "ya lo sé". Al instante me di cuenta de que mi reacción había sido absurda, no sólo para este niño en particular sino también para aquellos quienes que me habían dicho con anterioridad que los molestaban por ser negros o morenos y a quienes había respondido de manera similar.

Este niño sabe y siente que no hay ningún inconveniente en ser güero; para él, su tono de piel no es el problema e incluso en otros momentos lo escuché haciendo comentarios negativos sobre los negros o morenos (Diario de campo, 2012). A este alumno no le gusta que lo molesten y sin duda le afecta este tipo de discriminación -como él mismo hace bien en llamar-, pero cuando afirma que lo tratan mal "por ser güero" de ningún modo se siente insultado. Él sabe y siente que no hay nada de malo en él, por eso me dice "ya lo sé", cuando le doy mi absurda respuesta. En cambio, aun cuando hago vanos intentos para que otros niños a quienes molestan por ser negros o "prietos" se sientan mejor consigo mismos, no logro más que una reiteración de que no les gusta su tono de piel, pues sienten y piensan que hay algo malo en ellos.

Esta forma de discriminación también es una doble articulación de diferenciación y exclusión, pero mientras este niño está convencido de que no hay nada malo en su tono de piel, aquellos que enfrentan discriminación por tener la piel más oscura sí creen que tienen algo mal. A partir de este aspecto podemos distinguir entre el bullying que hace parte de una estructura racista y otros tipos de acoso escolar. Ello se debe a la manera en que históricamente se ha configurado la discrimina- 
ción racista en México y otros países. Tal como Plous (2003: 19-22) explica, las personas que son objeto de estereotipos pueden pensarse a sí mismos en función de éstos.

Eduardo Restrepo llama "endorracismo" al racismo interiorizado, y al respecto explica que "el racismo no sólo se dirige hacia otros individuos o colectividades, sino que puede ser dirigido hacía el sí mismo como individuo o a la colectividad propia" (Restrepo, 2012: 179). De este modo, las personas pueden rechazar sus propias prácticas culturales y reproducir estereotipos racistas sobre sí mismos u otros miembros de su colectividad, además de preferir un tono de piel diferente al propio o al que se asocia al grupo al cual pertenecen. En este sentido, es importante recordar que el tono de piel oscuro de ningún modo es un atributo negativo en sí mismo, pero histórica y socialmente se ha construido como tal y es sólo en dicha medida que se le considera un "estigma" (Goffman, 2006).

\section{Reflexiones finales}

El racismo se aprende, se vive, se reproduce y se busca combatir en la escuela. De acuerdo con Van Dijk (1988), la escuela reproduce el racismo a partir del discurso y diversos hechos comunicativos que abarcan los libros de texto, las lecciones de los docentes, las conversaciones y otro tipo de interacciones sociales. Para este mismo investigador, las personas participan de acciones discriminatorias "cuando forman, adaptan, transmiten y comparten cogniciones sociales relevantes con respecto tanto a su propio grupo como también a los grupos minoritarios" (Van Dijk, 1988: 134-135). Como he mostrado en este artículo, el bullying tiene precisamente esta capacidad para las y los niños en contextos escolares, ya que se trata de una manera de formar, adaptar, transmitir y compartir prejuicios y estereotipos racistas.

Para los niños de la Costa Chica, discriminar es insultar o molestar a otros por algún motivo, dentro de los cuales se encuentra la "raza" a la cual se considera que pertenecen las personas. En cambio, las definiciones jurídicas y científicas acerca de la discriminación suelen hacer más énfasis en la privación de algún derecho. Es interesante contemplar la manera en que los niños construyen estos conceptos a partir de las experiencias de su cotidianeidad, en particular considerando la relevancia de la educación escolar de la cual son parte.

A pesar de que los niños suelen hacer énfasis en los comentarios negativos o insultos por el tono de la piel, las experiencias de discriminación racista en contextos escolares de ninguna manera se limitan a ello. La educación escolarizada de la Costa Chica tiene un papel importante en la reproducción del racismo, puesto que la mayoría de los maestros comprenden la diversidad humana de manera racializada, mientras que otros emiten opiniones francamente racistas sobre los negros o morenos, al repetir estereotipos sobre su inteligencia, fuerza o sexualidad (Masferrer, en prensa). Ciertos docentes tratan de manera diferenciada a sus alumnos de acuerdo al color de su piel, o permanecen en silencio ante el bullying entre pares por este mismo motivo. Afortunadamente también hay maestros preocupados por la discriminación racista que procuran atender estos casos, muchas veces de la mano de las organizaciones civiles negras o afromexicanas de la región. En cambio, el 
Estado mexicano no ha emprendido acciones para erradicar la discriminación racista de los contextos escolares ni ha modificado los libros de texto, a pesar de diversos esfuerzos y procesos de comunicación que se han establecido con instancias de la SEP. ${ }^{9}$

Los casos de discriminación racista que presenté muestran la doble articulación de diferenciación y exclusión a la cual hace referencia Eduardo Restrepo en sus estudios sobre el racismo. Uno de los criterios para establecer diferenciaciones entre las personas es la "raza", término que en la región se asocia al tono de piel de las personas y otras características somáticas como la forma del cabello, pero que también hace alusión a la familia y el grupo de pertenencia, así como al lugar de procedencia (Masferrer, 2014b). Precisamente las palabras de Rosa, de quien hablé al inicio de este artículo, expresan sus conocimientos sobre la historia de los negros, pero también dan cuenta de la discriminación que observa y vive en su cotidianeidad, cuando imagina que puede saber si alguien es moreno: "yo no me siento contigo porque tú eres moreno".

\section{Bibliografía}

Aguilar Nery, Jesús (2012). "Diferencia racial en docentes de educación básica de Tijuana y Tecate. Un estudio exploratorio". En: Culturales, vol. 8, núm. 15, enero-junio. México: Universidad Autónoma de Baja California, pp. 47-80.

Allport, Gordon (1954). The nature of prejudice. Cambridge: Addison-Wesley Publishing Company.

Álvarez Lilian, Patricia Ávila, Bulmaro Reyes, Valentina Cantón, Adriana Corona, Esther Juárez y Norma Romero (2011 a). Formación civica y ética. Quinto grado. México: SEP (ciclo escolar 2012-2013).

(2011 b). Formación cívica y ética. Sexto grado. México: SEP (ciclo escolar 2012-2013).

Ballesteros Páez, María Dolores (2014). "El presente del pasado y la construcción de identidad(es). Continuidades y cambios en la producción de los libros de texto de Historia de México de Educación Secundaria (1993-2012)", tesis de doctorado en Ciencias Sociales. Monterrey: Tecnológico de Monterrey.

Baronnet, Bruno (2013). "Racismo y discriminaciones en el sistema educativo mexicano". En: Ascencio, Gabriel (coord.). Teoría y práctica de la educación intercultural en Chiapas. México: UNAM, pp. 63-79.

Barquín Cendejas, Alfonso (2015). Antropología y poder político. El ejercicio de poder en las políticas de educación intercultural. México: INAH.

9 En 2012, 2013, 2014 y 2015, María Elisa Velázquez, Gabriela Iturralde y la autora de este artículo, hemos estado en comunicación con autoridades de la SEP para modificar los libros de texto obligatorios. Sin embargo, hasta el momento las reuniones y los documentos que se han entregado no han rendido frutos. Por lo general se aduce falta de recursos, burocracia institucional y cambios frecuentes de personal. 
Barrón Pastor, Juan Carlos (2008). "Promoviendo relaciones interculturales. Racismo y acción afirmativa en México para indígenas en Educación Superior”. En: Trace, núm. 53. México: CEMCA, pp. 22-35.

Castellanos Guerrero, Alicia y Juan Manuel Sandoval (coords.) (1998). Nación, racismo e identidad. México: Nuestro Tiempo.

Castellanos Guerrero, Alicia (2000). “Antropología y racismo en México”. En: Desacatos, núm. 4. México: CIESAS, pp. 1-28.

(coord.) (2003). Imágenes del racismo en México. México: UAM/Plaza y Valdés.

Comisión Nacional de los Derechos Humanos (CNDH) (2012). La discriminación y el derecho a la no discriminación. México: CNDH.

Comisión Nacional para el Desarrollo de los Pueblos Indígenas (CDI) (2012). Informe final de la consulta para la identificación de comunidades afrodescendientes de México. CDI, México.

Consejo Nacional para Prevenir la Discriminación (Conapred) (2011). Guía para la acción pública de la población afrodescendiente en México. México: Conapred.

Coronado, Marcela y Patricia Mena (coords.) (2010). Lengua y cultura en procesos educativos: investigaciones en Oaxaca. Oaxaca: UPN.

Essed, Philomena (1991). Understanding Everyday Racism. An interdisciplinary Theory. California: Sage Publications.

Gall, Olivia (2004). "Identidad, exclusión y racismo: reflexiones teóricas y sobre México". En: Revista Mexicana de Sociología, año 66, núm. 2, abril-junio. México: UNAM, pp. 221-259.

Gallardo Gutiérrez, Ana Laura (2014). "Racismo y discriminación en el sistema educativo mexicano: claves desde las reformas a la educación básica nacional en el siglo XXI (2006 y 2011)”, tesis de doctorado en pedagogía. México: UNAM.

Gnade, Jill Renee (2008). "Raza, racismo y educación escolar en México", tesis de doctorado en Estudios Latinoamericanos. México: UNAM.

Goffman, Erving (2006). Estigma. La identidad deteriorada. Buenos Aires: Amorrortu.

Gómez Izquierdo, Jorge (1991). El movimiento antichino en México (1871-1934). Problemas del racismo y del nacionalismo durante la Revolución Mexicana. México: INAH. (coord.) (2005). Los caminos del racismo en México. México: Plaza y Valdés.

Hoffmann, Odile (2008). "Entre etnicización y racialización: los avatares de la identificación entre los afrodescendientes en México”. En: Castellanos, Alicia (coord.), Racismo e identidades. Sudáfrica y afrodescendientes en las Américas. México: UAM, pp. 163-176.

Instituto Nacional de Estadística y Geografía (INEGI). (2013). Perfil sociodemográfico de localidades con presencia de población afromexicana de Oaxaca, México: INEGI.

— (2015). Encuesta Intercensal 2015, México: INEGI. Disponible en: www.inegi.org.mx/est/ contenidos/Proyectos/encuestas/hogares/especiales/ei2015 
Lewontin, Richard (1972). The Apportionment of Human Diversity. En: Journal of Evolutionary Biology, vol. 6, pp. 381-398.

Martínez Buenabad, Elizabeth (2008). "Análisis de las relaciones interétnicas. Niños indígenas migrantes desde una escuela periférica de la ciudad de Puebla", tesis de doctorado, México: CIESAS.

Masferrer León, Cristina (2011). "La enseñanza sobre los africanos y afrodescendientes en la educación primaria y secundaria de México". En: Afrodescendencia. Aproximaciones contemporáneas de América Latina y el Caribe, Centro de Información de las Naciones Unidas para México, Cuba y República Dominicana, pp. 150-157.

(2014a). "Racismo, ignorancia y olvido. La esclavitud y las personas de origen africano en la educación primaria y secundaria de México". En: Serna, Jesús y Fernando Cruz (comps.). Afroindoamérica. Resistencia, visibilidad y respeto a la diferencia. México: UNAM, pp. 141158.

— (2014b). "Aquí antes se llamaba Poza Verde. Conocimientos de niños de la Costa Chica sobre su pueblo y lo negro, tesis de maestría en Antropología Social". México: CIESAS.

—_ (en prensa). "La afrodescendencia en la educación básica de México: libros de texto nacionales y prácticas docentes locales". En: Cottias, Myriam, Marie-Albane de Suremain y Eric Mesnard, Enseigner les traites, les esclavages, leurs abolitions et leurs heritages. París: Karthala.

Molina Ludy, Virginia, (1995). "La ideología subyacente en la discriminación hacia los pueblos indios”. En: Barceló, Raquel, María Portal y Martha Sánchez (coords.), Diversidad étnica y conflicto en América Latina. El indio como metáfora en la identidad nacional, vol. II. México: UNAM, Plaza y Valdés, pp. 147-174.

Moreno Núñez, Paula (2003). "La esclavitud: sus formas, tipologías y tipos en la historia de México y el mundo", tesis en Etnohistoria. México: ENAH.

París Pombo, María Dolores (1999). Racismo y nacionalismo: la construcción de identidades excluyentes. En: Política y cultural, núm. 12. México: UAM, pp. 53-76.

Plous, S. (2003). The Psychology of Prejudice, Stereotyping and Discrimination: An Overview, (pp. 1-25), recuperado el 15 de mayo de 2014 desde: www.simplypsychology.org/Prejudice. pdf. (Originalmente publicado en S. Plous (ed.), Understanding Prejudice and Discrimination. Nueva York: McGraw-Hill, pp. 3-48).

Ramírez, Carlos (2007). "De genes, razas y racismo" (parte I). En: Revista del Instituto Nacional de Higiene Rafael Rangel, vol. 38, núm. 2, diciembre. Caracas: INHRR, pp. 64-65. (2009). "De genes, razas y racismo" (parte II). En: Revista del Instituto Nacional de Higiene Rafael Rangel, vol. 40, núm. 1, enero. Caracas: INHRR, pp. 64-68.

Restrepo, Eduardo (2012). Intervenciones en teoría cultural. Popayán: Universidad del Cauca. Rodríguez Zepeda, Jesús (2008). Un marco teórico para la discriminación. México: Conapred. Saco, José Antonio (2002). Historia de la esclavitud. Cuba: Imagen Contemporánea. 
Urías Horcasitas, Beatriz (2007). Historias secretas del racismo en México, 1920-1950. México: Tusquets.

UNICEF. Convención sobre los Derechos del Niño. Recuperado el 15 de mayo de 2014 desde: www. unicef.org/mexico/spanish/mx_resources_textocdn.pdf

Velasco Cruz, Saúl (2016). "Racismo y educación en México". En: Revista Mexicana de Ciencias Políticas y Sociales, año LXI, núm. 226. México: UNAM, pp. 379-408.

Wieviorka, Michel (2009). El racismo: una introducción. Barcelona: Gedisa.

Yankelevich, Pablo (coord.) (2009). Nación y extranjería. La exclusión racial en las políticas migratorias de Argentina, Brasil, Cuba y México. México: UNAM.

Van Dijk, Teun (1988). "El discurso y la reproducción del racismo". En: Lenguaje en contexto, núm. 1. Buenos Aires: Universidad de Buenos Aires, pp. 131-180.

Velázquez, María Elisa y Gabriela Iturralde (2012). Afrodescendientes en México. Historias contra el olvido y la discriminación. México: Conapred.

Recibido: 30/04/16

Dictaminado: $23 / 06 / 16$

Corregido: 02/07/16

Aceptado: 16/07/16 